\title{
Cingulate Cortex
}

National Cancer Institute

\section{Source}

National Cancer Institute. Cingulate Cortex. NCI Thesaurus. Code C52713.

Part of the medial aspect of the cerebral cortex. 